\title{
DIRECT AC-AC PROPULSION SYSTEM USING MATRIX CONVERTER AND 5Ф TRACTION MOTOR FOR HEV VEHICLE
}

\begin{abstract}
The paper deals with direct AC-AC propulsion system using [nx5] matrix converter and five-phase traction induction motor (IM) for hybrid electric vehicle (HEV) including electronic differential. Using the direct AC-AC system, in comparison to classical rectifier-inverter with DC link, features smaller on-state semiconductor switches losses and consequently higher efficiency of power train of the vehicle. The major advantage of using a five-phase machine instead of three-phase one is in smaller torque pulsation and better fault tolerance under one phase of supply.

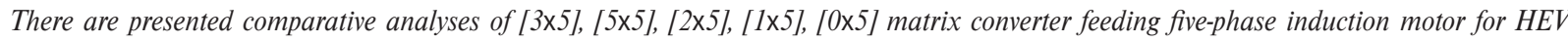
vehicle. Modeling and simulation are done using Matlab-Simulink environment, and simulation experimental results are given in the paper.

Keywords: AC/AC power train, matrix converter, five-phase induction motor, electric drive, bidirectional switch, modeling and simulation
\end{abstract}

\section{Introduction}

Automobile propulsion system needs to develop maximum torque at zero speed. This cannot be achieved with conventional internal combustion engines (ICE). For ICE vehicles efficiency is rather small at low speeds and has a maximum value near rated speed. The usual arrangement of the electrical as well as non-electrical vehicles involves only one traction engine driving two wheels using a differential gear. In contrast, HEV and EV vehicle with multiple motor-wheels may represent benefits such as improving vehicle performance with better weight distribution and no power failure in the differential and the possibility to control the acceleration of each wheel separately for better stability in difficult or dangerous situations. Concept of HEV with ICE-electric motor aims to overcome the disadvantages of the pure electric vehicles, whose engines are powered by electric batteries: the limited duration of use (low autonomy) and time needed to recharge the batteries.

The possible operating modes of hybrid electric drive trains are [1]: pure electric: ICE is stopped and the vehicle is propelled only by batteries energy, pure engine mode: the vehicle is powered with energy provided by electric generator driven by engine. The batteries do not provide and do not take energy from the drive train. Hybrid mode: The traction power is drawn from both the engine-generator and the batteries. Engine traction and battery charging mode: The ICE-generator provides the energy needed for the batteries charging and the propulsion vehicle. Regenerative braking mode: the engine is turned off and the traction motor is operated as generator and the energy provided is used to charge the batteries. Batteries charging mode: The engine - generator charges the batteries and the traction motor is not supplied. Hybrid batteries charging mode: both the engine-generator and the traction motor operate as generator to charge the batteries.

Traction drive used in electric vehicles can be divided into two categories: (a) single-drive system and (b) multi-drive system. With multi-drive systems, the motor controllers must additionally be configured to provide an electronic differential effect i.e. they must also perform a similar function as their mechanical differential counterpart. Thus, the electronic differential must take into account the speed difference between the two wheels when cornering.

Configuration with motor-wheels allows flexibility of the car; removes the central drive motor and associated transmission parts of the propulsion system of the vehicle. The main advantage of the electric motor in the wheel is adjustable traction and individual braking torque with high precision without ingestion gearbox, drive shaft, differential gear and other complex and heavy parts of power transmission [2,3]. One of such a traction system is shown in Figure 1.

\footnotetext{
* Branislav Dobrucky, Slavomir Kascak, Michal Prazenica, Pavel Pavlasek

Department of Mechatronics and Electronics, Faculty of Electrical Engineering, University of Zilina, Slovakia E-mail: branislav.dobrucky@fel.uniza.sk
} 


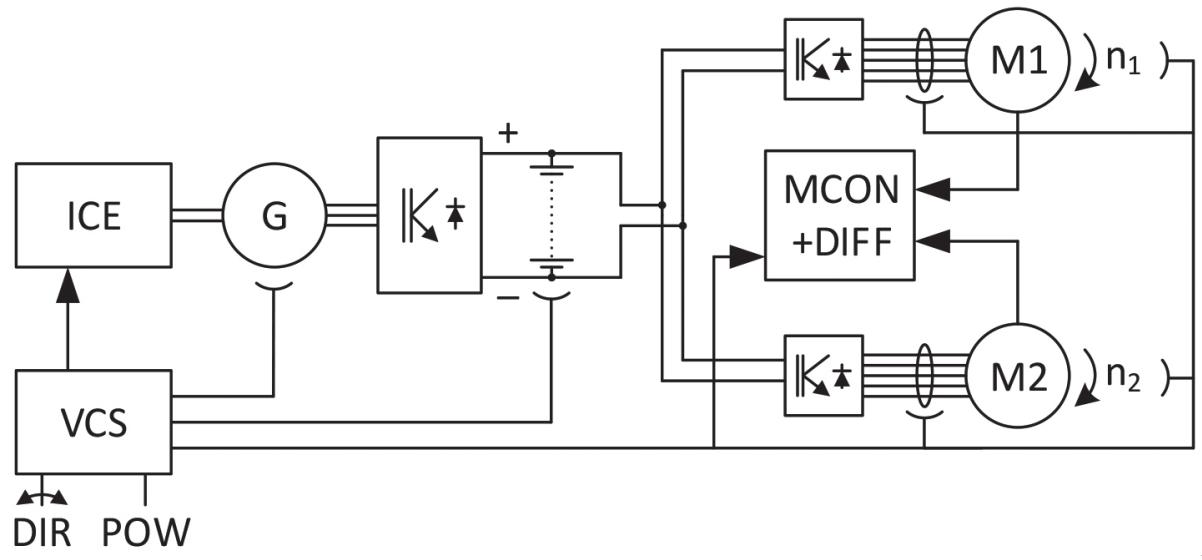

Figure 1 Series HEV with two VSI converters two motor wheels and electronic differential

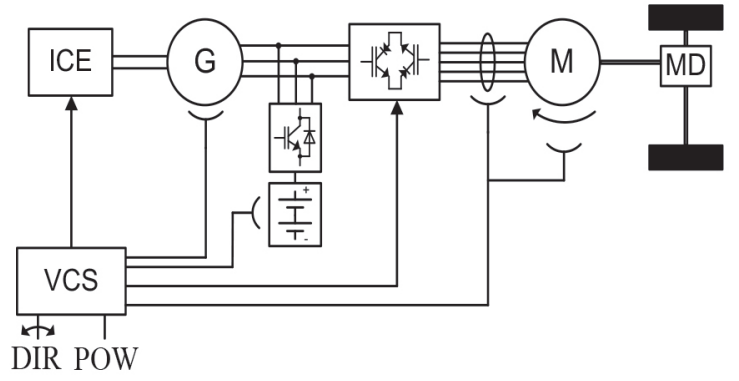

a)

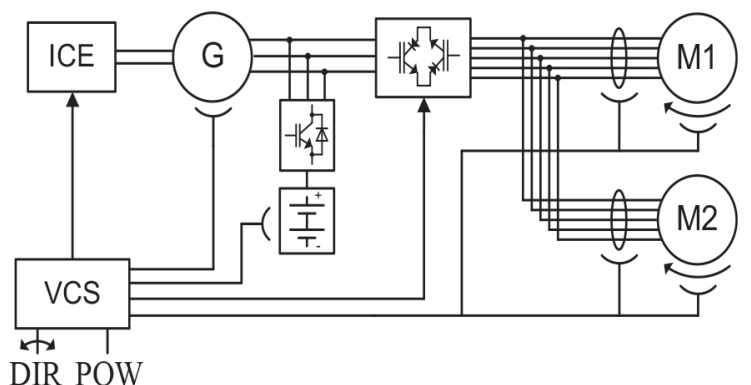

b)

Figure 2 Direct AC-AC propulsion system with one [3×5] matrix converter and mechanical differential (a) or parallel connected two 5ФIM (b)

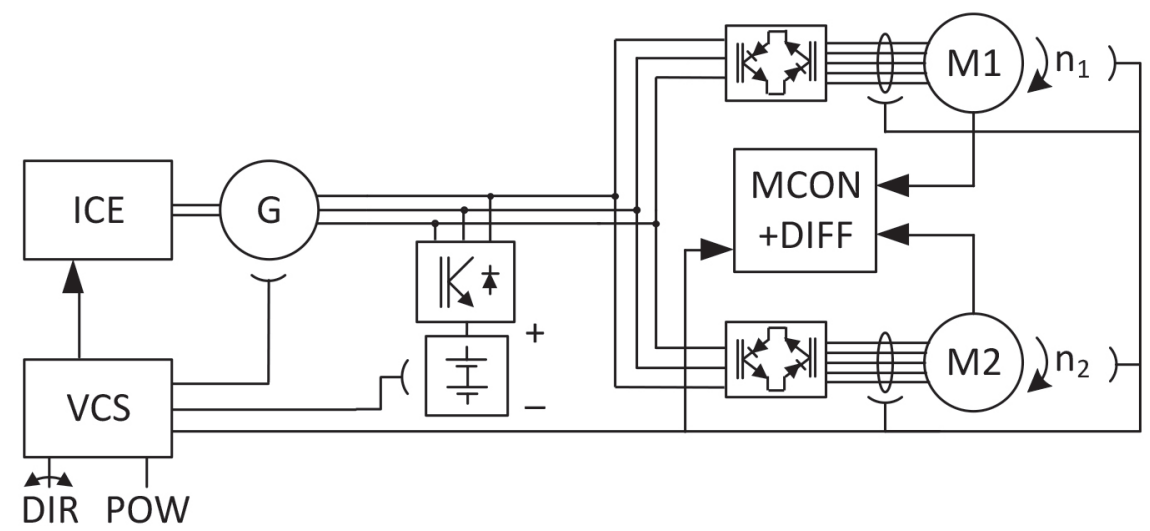

Figure 3 Direct AC-AC propulsion system with two [3×5] matrix converter and two 5ФIM traction motor wheels

Another approach with high frequency AC interlink [1x3] $\mathrm{MxC}$ is presented in $[4,5]$.

\section{New AC/AC traction propulsion system}

When omitting systems with mechanical differential used for propelling the two back-driving wheels of the vehicle Figure 2a, there still remain two different configurations of the direct $\mathrm{AC} /$ $\mathrm{AC}$ traction systems. One of them, called independent control of machines fed by one [3x5] matrix converter, Figure 2b. But, the papers $[6,7]$ explain that, although parallel multi-phase multi-motor drives and series connected multi-phase multi-motor drive systems are feasible and in principle offer good quality of dynamic performance as well, they do not hold a real prospect for industrial applications so far.

So, proposed propulsion system is presented in Figure 3 and comprises of two machines (PMSM, IM, SRM,..) that ensure the drive, including an electronic differential. 


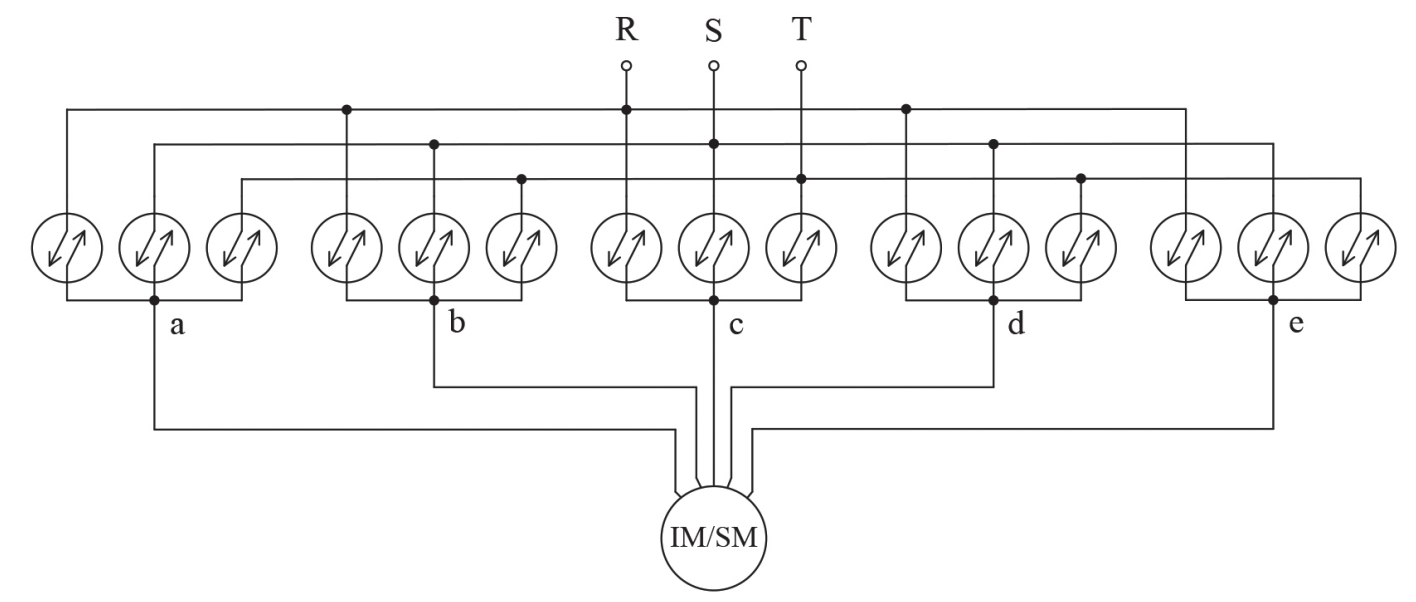

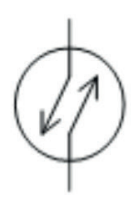
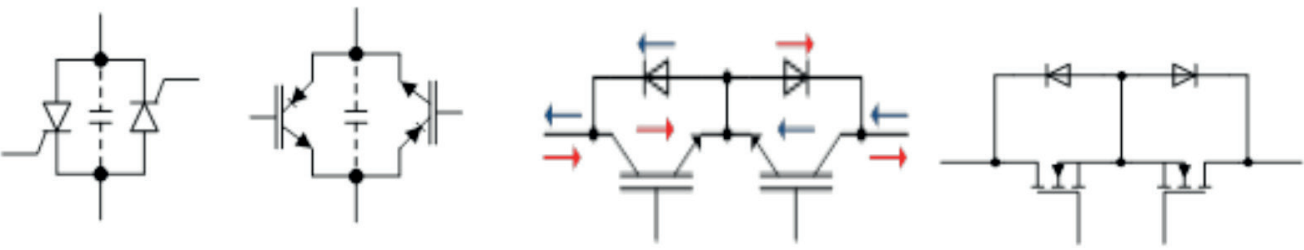

b)

Figure 4 Principle scheme of $3 \times 5$ matrix converter (a) with antiparallel or inversely connected BDS switches (b)

The proposed traction system consists of two [3×5] matrix converters and two five-phase machines (IM) that ensure the drive of two back-driving wheels. The control of them is provided by an electronic differential offering good quality of a dynamic performance of the HEV vehicle. Propulsion system can be operated from both ICE engine and/or traction accu-battery.

The main difference between series HEV propulsion system $\mathrm{AC} / \mathrm{DC} / \mathrm{AC}$ (Figure 1) and direct $\mathrm{AC} / \mathrm{AC}$ is that the second one does not comprise DC interlink between rectifier a VSI inverter. Thus, instead of voltage drops on rectifier- and inverter switches are substituted by a voltage drop on bidirectional switches of $\mathrm{MxC}$ only. If we consider just simple antiparallel connection of switches, then the total resulting voltage drop will be twice lesser. On the other hand, the operation from the accu-battery should be provided by additional converter.

Principle schematics of [3×5] matrix converter is shown in Figure 4a. It comprises 15 bidirectional switches (BDS) consisting of two semiconductor devices: turn-off GTO thyristors or reverse blocking RB IGBT transistors, Figure $4 \mathrm{~b}$.

The main problem of such bidirectional connection of BDS is withdrawing the energy of switched-off $\mathrm{MxC}$ circuit. Therefore, during inter-commutation of switches active snubbers should be used. There is necessary five snubber group- each for single phase a), b), c), d), e) of the motor. The basic scheme of this connection [8-10] is presented in Figure 5.
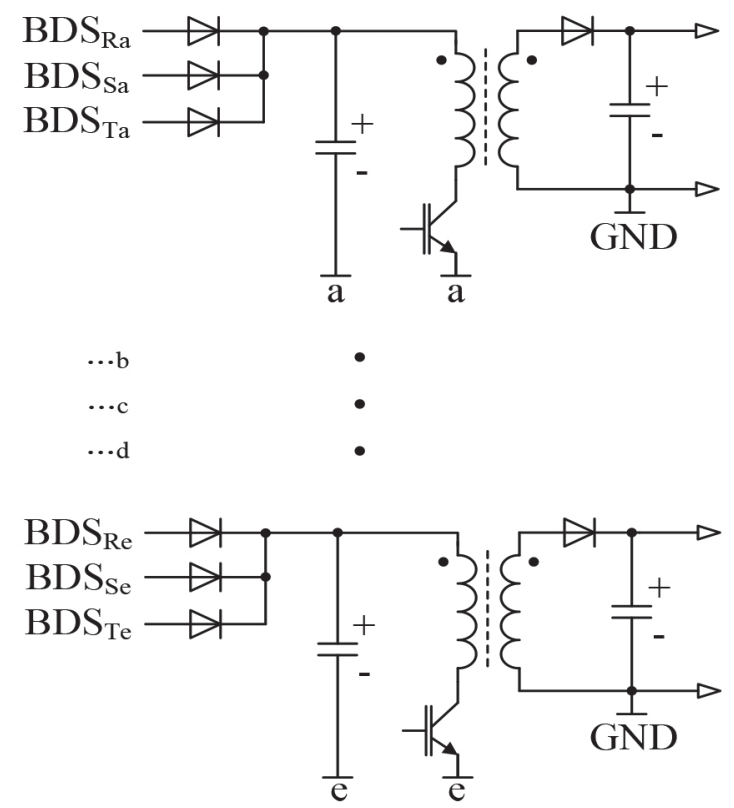

Figure 5 Basic connection of snubber groups with active transfer of commutation energy

\section{Modelling and analysis of $[3 \times 5]$ matrix converter}

The MxC can be studied based on two separated virtual stages reflecting the two stages of the conventional converter (rectifier-inverter) [11-13], Figure 6. Since at any given time at least one phase of the power supply voltage is positive and at least 


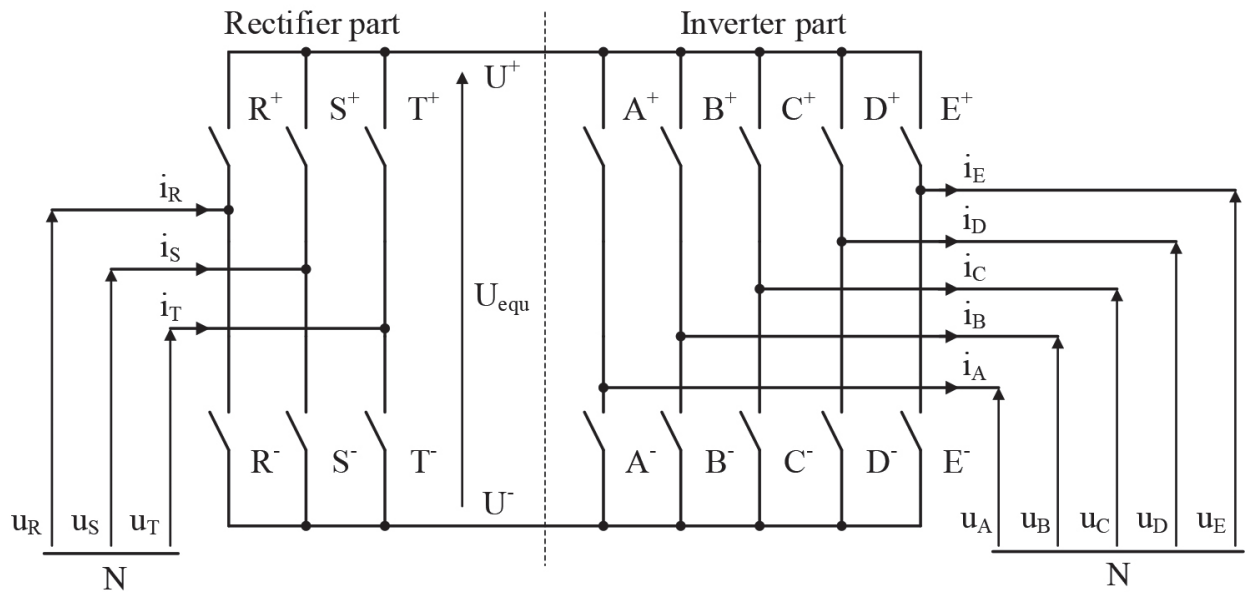

Figure 6 Virtual model of indirect MxC with fictitious DC link

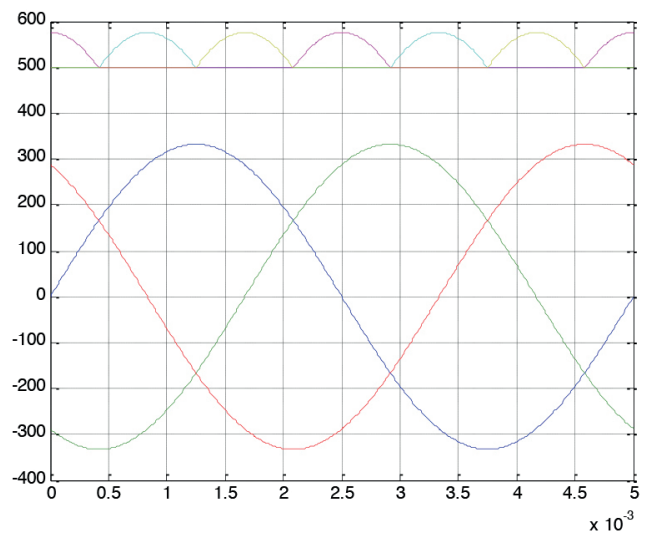

a)

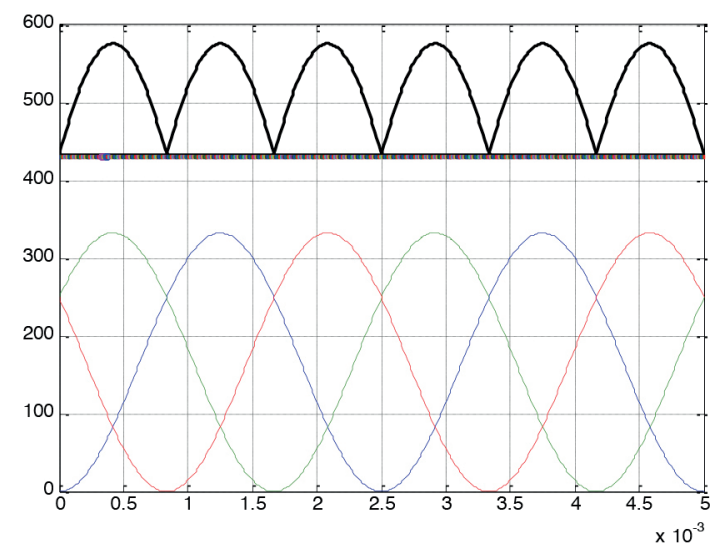

b)

Figure 7 Time waveforms of fictitious DC link voltage (a) and voltage square function (b) $x$ : time, $y: u_{A}, u_{B}, u_{C} u_{A}$, and $u_{\text {equ }}$ voltages

another phase is negative, the fictitious DC link voltage is given by difference between $U^{+}$and $U^{-}$potentials.

Then, MxC output voltage can be calculated by these Equations (1)

$\left[\begin{array}{l}u_{a} \\ u_{b} \\ u_{c} \\ u_{d} \\ u_{e}\end{array}\right]=\left[\begin{array}{ll}u_{m 1} & 1-u_{m 1} \\ u_{m 2} & 1-u_{m 2} \\ u_{m 3} & 1-u_{m 3} \\ u_{m 4} & 1-u_{m 4} \\ u_{m 5} & 1-u_{m 5}\end{array}\right]\left[\begin{array}{lll}R^{+} & S^{+} & T^{+} \\ R^{-} & S^{-} & T^{-}\end{array}\right]\left[\begin{array}{l}u_{R} \\ u_{S} \\ u_{T}\end{array}\right]$

where $u_{m k}=r \cos (\varphi) \sin \left(\omega_{0} t-\frac{2 \pi}{5}(k-1)\right)+1 / 2$ for $k=1 \ldots 5$

$r=\frac{\cos (\varphi-\pi / 3)}{\cos (\varphi)}$ and $\varphi=\left.\omega t\right|_{\bmod \left(\frac{\pi}{3}\right)}-\pi / 6$

$R^{+} \ldots T^{-}$are logical variables for the $\max$ and $\min$ input phase voltage.
Average values of the fictitious DC interlink can be calculated. Derivation based on definition Equations (2), (3) is given in Appendix for 3-, 5-, and 2-phase systems. Average values of the fictitious DC interlink voltage for 3-phase system

$U_{D C a v}=\frac{6}{\pi} U_{m} \int_{\pi / 3}^{\pi / 2} \sin (\omega t) d t$

Since the power of interlink and also torque of IM are dependent on voltage square function $\left(P_{a v} \sim U_{\text {rms }}^{2} /|Z| \rightarrow T_{\text {mech }} \sim P_{a v} / \omega_{\text {mech }}\right)$ the average values of the fictitious DC interlink voltage square function for 3-phase system can be expressed for 3-phase system as

$U^{(2)}{ }_{D C a v}=\frac{6}{\pi} U_{m} \int_{\pi / 3}^{\pi / 2} \sin ^{2}(\omega t) d t$

The fictitious DC link voltage and voltage square function are presented in Figure 7a,b. 
Table 1 Average values of the fictitious DC interlink

\begin{tabular}{ccc}
\hline Supply system & $U_{D C a v} \times U_{m}$ & $U_{D C a v}^{(2)} \times U_{m}$ \\
\hline 3-phase system & $0.955 U_{m}$ & $0.913 U_{m}$ \\
5-phase system & $0.984 U_{m}$ & $0.968 U_{m}$ \\
2-phase system & $0.900 U_{m}$ & $0.818 U_{m}$ \\
\hline
\end{tabular}

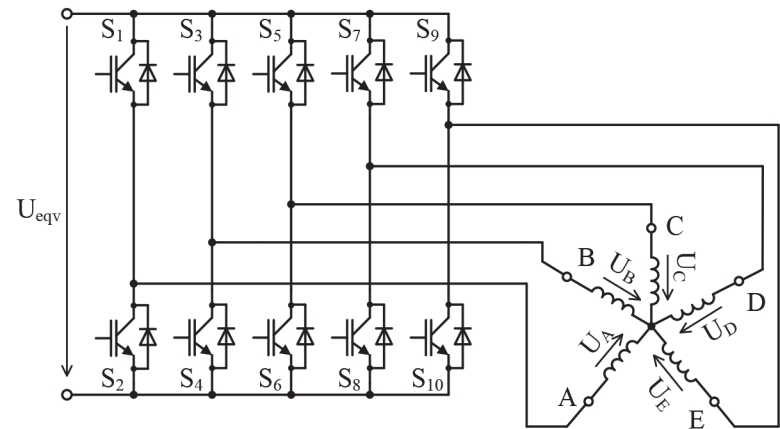

Figure 8 Equivalent circuit scheme of inverter stage of indirect $M \times C$ with fictitious DC interlink and five-phase IM motor

Results of both voltage average value parameters for all three systems are shown in the Table 1.

Based on these values the important parameters as ratios $\frac{U_{m}}{U_{D C a v}}$ and $\frac{U_{m}}{U^{(2)}{ }_{D C a v}}$ can be calculated. Values of the ratios of both parameters are shown in the Table 2 .

It can be deduced from Table 2 that by given power, also torque, the 3-phase machine should be oversized against 5-phase one by $\sim 6 \%$. By other words, the maximum power and torque of 3-phase and 2-phase machines will be greater against 5-phase one by $\sim 6 \%$ and/or $\sim 19 \%$, respectively. So, the compromise between these three propulsion systems is three-phase supply with $3 \Phi S G$ generator, [3x5] matrix converter five-phase traction motor 5 $\Phi \mathrm{IM}$.

\section{Modeling of drive with 5ФIM traction motor fed by fictitious DC link ten-pulse frequency converter}

Based on above, the derivations of the equivalent schematics for modelling and simulation can be introduced, Figure 8 .

Then, stator voltage of $5 \Phi \mathrm{IM}$ motor in vector form is $[14,15]$

$$
\begin{aligned}
u_{s} & =\operatorname{Re}\left(u_{s}\right)+j \operatorname{Im}\left(u_{s}\right)= \\
& =\frac{2}{5}\left(u_{a}+u_{b} e^{j \frac{2 \pi}{5}}+u_{c} e^{j \frac{4 \pi}{5}}+u_{d} e^{j \frac{6 \pi}{5}}+u_{e} e^{j \frac{8 \pi}{5}}\right)
\end{aligned}
$$

and possible scalar form:

$u_{s}=\operatorname{Re}\left(u_{s}\right)+j \operatorname{Im}\left(u_{s}\right)=u_{\alpha}+j u_{\beta}$. Similarly, the current vector can be expressed as $i_{s}=i_{\alpha}+j i_{\beta}$.
Table 2 Ratios of both parameters $\frac{U_{m}}{U_{D C a v}}$ and $\frac{U_{m}}{U^{(2)}{ }_{D C a v}}$

\begin{tabular}{cccc}
\hline \multirow{2}{*}{ Supply system } & $U_{m}$ & $\frac{U_{m}}{U_{D C a v}}$ & $\begin{array}{c}\text { Oversizing } \\
\text { [per cent] }\end{array}$ \\
\hline 3-phase system & 1.047 & 1.095 & $9.5 \%$ \\
5-phase system & 1.017 & 1.033 & $3.3 \%$ \\
2-phase system & 1.111 & 1.222 & $22.2 \%$ \\
\hline
\end{tabular}

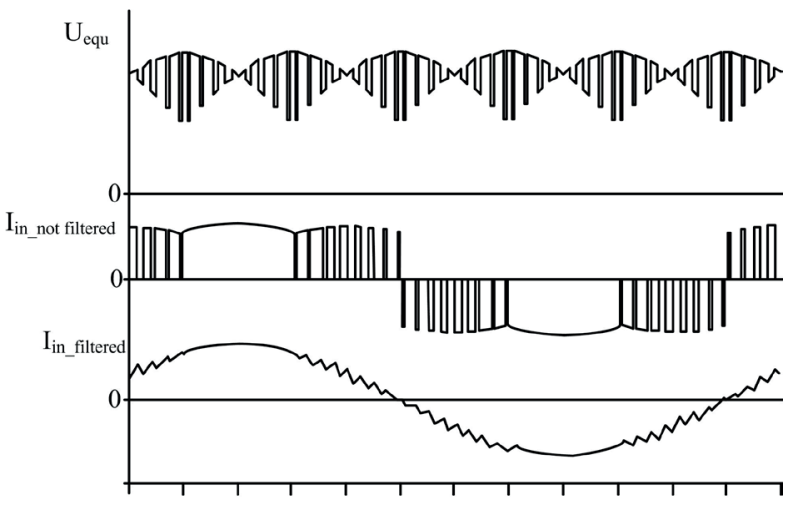

time $[\mathrm{s}]$

Figure 9 Principle of PWM modulation of [3×3] MxC under fictitious DC interlink

Consequently, the model of $5 \Phi \mathrm{IM}$ motor can be expressed by Equations (5), (6).

$\frac{d}{d t}\left(\begin{array}{c}i_{s} \\ i_{r} \\ \omega_{m}\end{array}\right)=A\left(\begin{array}{c}i_{s} \\ i_{r} \\ \omega_{m}\end{array}\right)+B\left(\begin{array}{c}u_{s} \\ u_{r} \\ 0\end{array}\right)$

where $A, B$ are matrices of system parameters

$A=\left(\begin{array}{cccc}-\frac{R_{r}}{L_{r}} & \omega_{r} & M \frac{R_{r}}{L_{r}} & 0 \\ -\omega_{r} & -\frac{R_{r}}{L_{r}} & 0 & M \frac{R_{r}}{L_{r}} \\ \frac{M R_{r}}{\sigma L_{s} L_{r}^{2}} & \frac{M}{\sigma L_{s} L_{r}}\left(\omega_{s}-\omega_{r}\right) & -\frac{R_{s}}{\sigma L_{s}} & \omega_{s} \\ \frac{M}{\sigma L_{s} L_{r}}\left(\omega_{s}-\omega_{r}\right) & \frac{M R_{r}}{\sigma L_{s} L_{r}^{2}} & -\omega_{s} & -\frac{R_{s}}{\sigma L_{s}}\end{array}\right) ;$

$B=\left(\begin{array}{cccc}1 & 0 & 0 & 0 \\ 0 & 1 & 0 & 0 \\ -\frac{M}{\sigma L_{s} L_{r}} & 0 & \frac{1}{\sigma L_{s}} & 0 \\ 0 & -\frac{M}{\sigma L_{s} L_{r}} & 0 & \frac{1}{\sigma L_{s}}\end{array}\right)$

and $\omega_{m}$ is calculated as

$\frac{d}{d t} \omega_{m}=\frac{T_{\text {elmg }}-T_{\text {load }}}{J_{m}}$

From the point of view of control strategies (PWM, SVC,) these are not particularly investigated in the paper. Nor special strategies during loss of one phase of the feeding source. Anyway, such strategies are commonly used, e.g. in the works [9-12], [14-16]. 


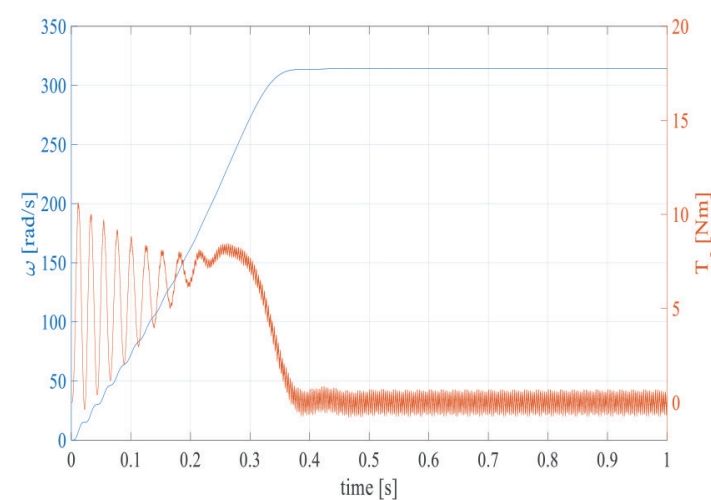

a)

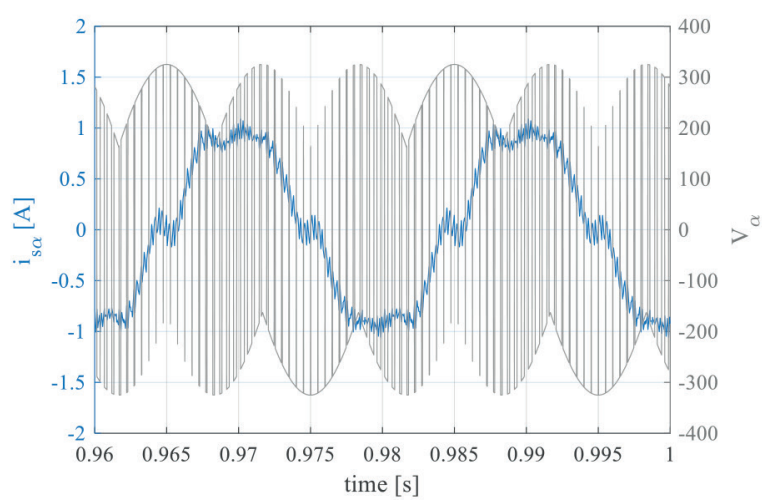

b)

Figure 10 Start-up of 5ФIM fed by [3×5] matrix converter for speed and torque (a), detailed waveforms of phase voltage and current at steady-state (b)

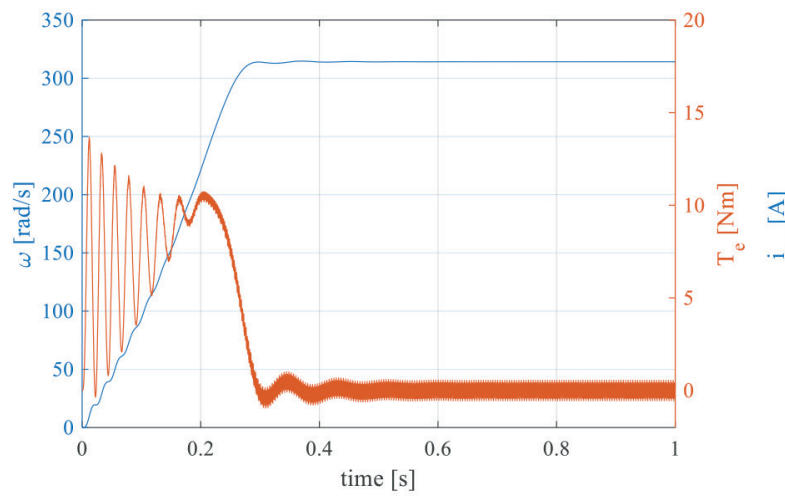

a)

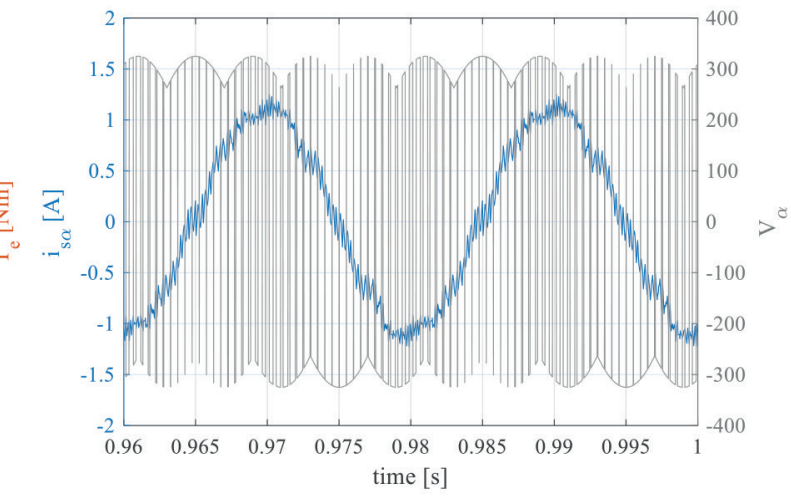

b)

Figure 11 Start-up of 5ФIM fed by [5×5] matrix converter for speed and torque (a), detailed waveforms of phase voltage and current at steady-state (b)

Possible PWM modulation for [3x3] matrix converter is shown in Figure 9.

\section{Simulation experiment results}

There are results of simulation experiments of five-phase induction motor 5 $\mathrm{IIM}$ with different supplies shown in Figures 10-14:

- $5 \Phi \mathrm{IM}$ fed by [3×5] matrix converter

- $5 \Phi I M$ fed by [5x5] matrix converter

- $5 \Phi I M$ fed by [2×5] matrix converter

- $5 \Phi \mathrm{IM}$ fed by [1 $\times 5]$ matrix converter

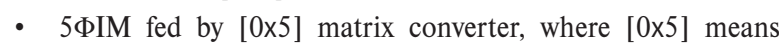
matrix converter with pure DC supply.

Simulations were done using fictitious voltage by Figure 7 and Figure 8 in Matlab Simulink environment.

It is clear that obtained results show that voltage is periodic and current follows the desired amplitude and frequency.

\section{Conclusions}

There have been investigated different supply systems:

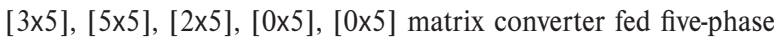
induction motor for HEV vehicle in the paper. 5ФIM traction motor has been chosen because five-phase motor drive with series or parallel connected motors is feasible and in principle offer good quality of dynamic performance. This is not possible with three-phase motors.

From the point of view of supply systems, the [3×5] MxC with $5 \Phi \mathrm{IM}$ system is good compromise from economic and industrial applications. The obtained results show that, the [5×5] MxC with $5 \Phi I M$ propulsion system reaches approximately results as the system supplied from DC source i.e. accu-battery. Besides, it is known that five-phase application has the following advantages in comparison to the three-phase supply application [12], [17]: The speed curve response time dynamics is faster, the torque curve has lower ripple rate, the value of the output voltage of the converter is higher. Furthermore, the amplitude of the output current in five 


\section{KomNllkCle}

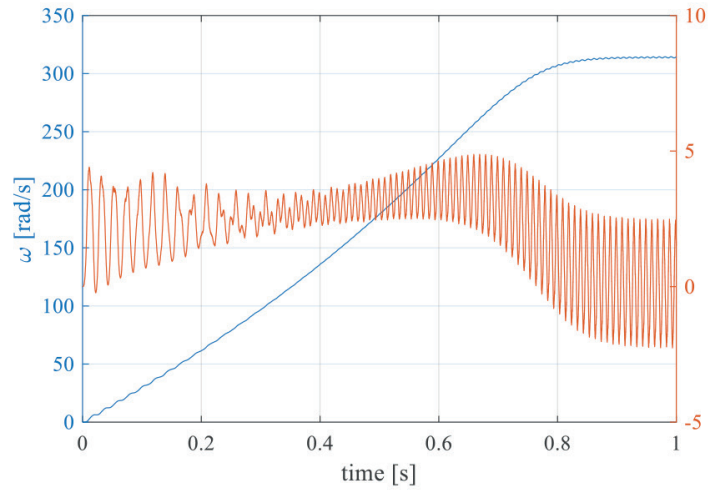

a)

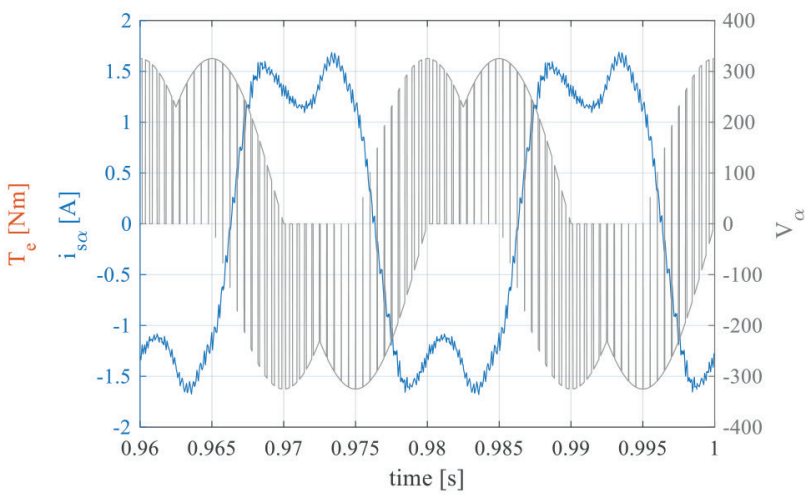

b)

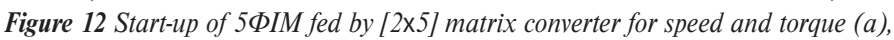
detailed waveforms of phase voltage and current at steady-state (b)

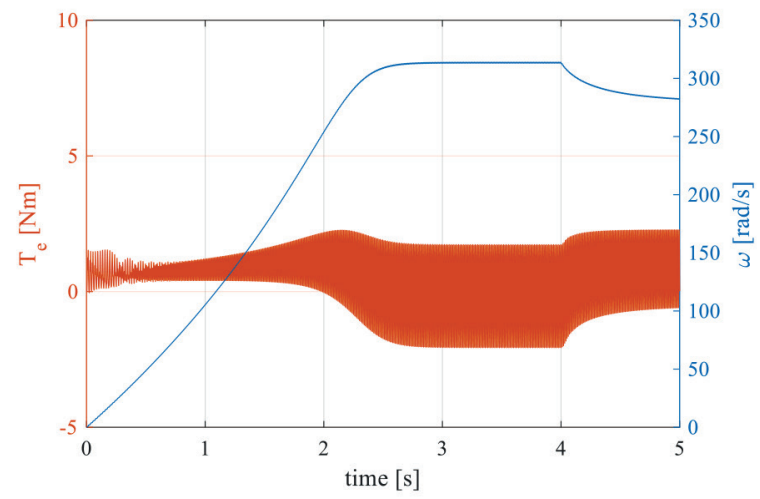

a)

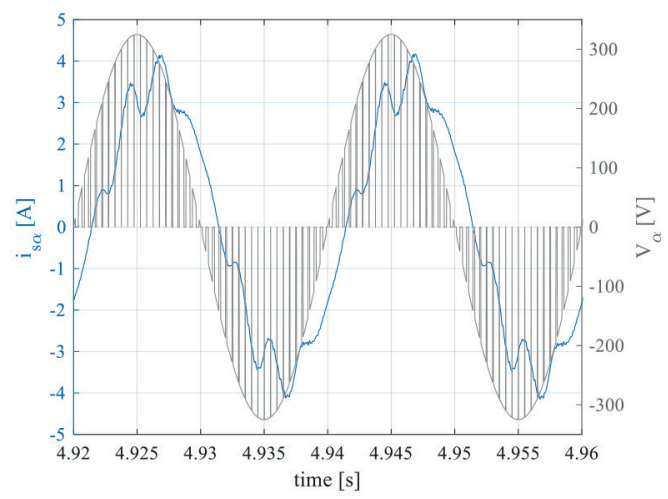

b)

Figure 13 Start-up of 5ФIM fed by [1×5] matrix converter for speed and torque (a), detailed waveforms of phase voltage and current at steady-state (b)

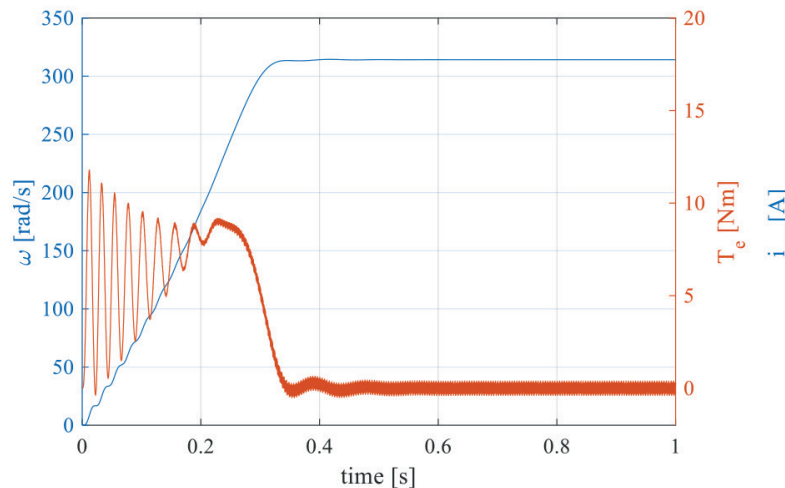

a)

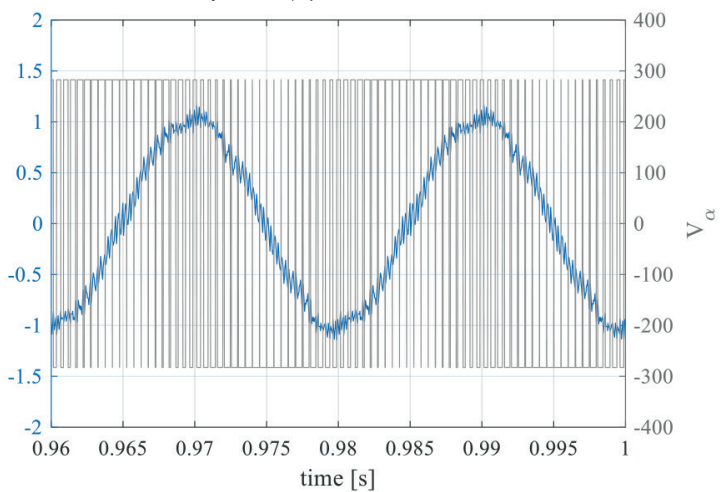

b)

Figure 14 Start-up of 5ФIM fed by [0×5] matrix converter for speed and torque (a), detailed waveforms of phase voltage and current at steady-state (b)

phase motors is reduced compared to the three-phase one which can prevent deterioration of the windings; it uses smaller gauge switches (reduces the cost of purchase and maintenance).

The present approach can be generalized for more than five-phase output and has some inherent advantages that make this application a very promising solution, especially when it is connected to a multiphase machine to profit mainly from all its benefits in industrial plant applications. 


\section{Appendix}

Average value of fictitious DC link since 3-phase supply

$$
\begin{aligned}
U_{D C a v} & =\frac{6}{\pi} U_{m} \int_{\pi / 3}^{\pi / 2} \sin (\omega t) d t=\frac{6}{\pi} U_{m} \cos \left(\frac{\pi}{3}\right)=\frac{3}{\pi} U_{m} \doteq \\
& \doteq 0.955 U_{m}
\end{aligned}
$$

thus ratio of $\frac{U_{m}}{U_{D C a v}} \doteq 1.047$.

Average value of fictitious DC link since 5-phase supply $U_{D C a v}=\frac{10}{\pi} U_{m} \int_{2 \pi / 5}^{\pi / 2} \sin (\omega t) d t=\frac{10}{\pi} U_{m} \cos \left(\frac{2 \pi}{5}\right) \doteq 0.984 U_{m}$ thus ratio of $\frac{U_{m}}{U_{D C a v}} \doteq 1.017$.

Average value of fictitious DC link since 2-phase supply

$$
\begin{aligned}
U_{D C a v} & =\frac{4}{\pi} U_{m} \int_{\pi / 4}^{\pi / 2} \sin (\omega t) d t=\frac{4}{\pi} U_{m} \cos \left(\frac{\pi}{4}\right)=\frac{2 \sqrt{2}}{\pi} U_{m} \doteq \\
& \doteq 0.900 U_{m}
\end{aligned}
$$

thus the ratio of $\frac{U_{m}}{U_{D C a v}} \doteq 1.111$.

Average value of fictitious DC link voltage square function for 3-phase supply

$$
\begin{aligned}
U_{D C a v}^{(2)} & =\frac{6}{\pi} U_{m} \int_{\pi / 3}^{\pi / 2} \sin ^{2}(\omega t) d t= \\
& =\frac{6}{\pi} U_{m}\left\{\frac{1}{2}\left[\left(\frac{\pi}{2}-\frac{\pi}{3}\right)-\frac{1}{2}\left(\sin 2 \frac{\pi}{2}-\sin 2 \frac{\pi}{3}\right)\right]\right\} \doteq \\
& \doteq 0.913 U_{m}
\end{aligned}
$$

where $\sin ^{2}(\omega t)=\frac{1}{2}\left[1-\cos (2 \omega t]\right.$ and ratio $\frac{U_{m}}{U^{(2)}{ }_{D C a v}} \doteq 1.095$.

Average value of fictitious DC link voltage square function for e 5-phase supply

$$
\begin{aligned}
U_{D C a v}^{(2)} & =\frac{10}{\pi} U_{m} \int_{2 \pi / 5}^{\pi / 2} \sin ^{2}(\omega t) d t= \\
& =\frac{10}{\pi} U_{m}\left\{\frac{1}{2}\left[\left(\frac{\pi}{2}-\frac{2 \pi}{5}\right)-\frac{1}{2}\left(\sin 2 \frac{\pi}{2}-\sin 2 \frac{\pi}{5}\right)\right]\right\} \doteq \\
& \doteq 0.968 U_{m}
\end{aligned}
$$

So, the ratio $\frac{U_{m}}{U^{(2)}{ }_{\text {DCav }}} \doteq 1.033$.

Average value of fictitious DC link voltage square function for 2-phase supply

$$
\begin{aligned}
& U_{D C a v}^{(2)}=\frac{4}{\pi} U_{m} \int_{2 \pi / 5}^{\pi / 2} \sin ^{2}(\omega t) d t= \\
& =\frac{4}{\pi} U_{m}\left\{\frac{1}{2}\left[\left(\frac{\pi}{2}-\frac{2 \pi}{5}\right)-\frac{1}{2}\left(\sin 2 \frac{\pi}{2}-\sin 2 \frac{\pi}{5}\right)\right]\right\} \doteq \\
& \doteq 0.818 U_{m} \\
& \text { and ratio } \frac{U_{m}}{U^{(2)}{ }_{D C a v}} \doteq 1.222 \text {. }
\end{aligned}
$$

\section{Acknowledgement}

The reported study was supported from Slovak Grant Agency VEGA by the grant No. 1/0928/15. Author also thanks to the R\&D operational program Modernization of Research Infrastructure in the Field of Electrotechnics, Electrotechnical Materials and Information-Communication Technologies, ITMS 26210120021 funded by the European regional development fund (ERDF).

\section{References}

[1] EHSANI, M., GAO, Y., EMADI, A.: Modern Electric, Hybrid-and Fuel Cell Vehicles. CRC Press, Boca Raton, USA, 2010.

[2] HARTANI, K., BOURAHLA, M., MILOUD, Y., SEKOUR, M.: Electronic Differential with Direct Torque Fuzzy Control for Vehicle Propulsion System. Turkısh Journal Of Electrical Engıneerıng Computer Sciences, 17(1), 21 -38, 2009.

[3] DOBRUCKY, B., ZASKALICKY, P., PAVLASEK, P.: Control of Hybrid-and Electrical Vehicle with Five-Phase IM Motor. Autobusy-Efficiency of Transport, 18(6), 1191-1195, 2017.

[4] GONTHIER, L., BERNOT, F., BOCUS, S. D., ELBAROUDI, S., BERTHON, A.: High-Efficiency Soft-Commutated DC-AC-AC Converter for Electric Vehicles. ElectroMotion, 5(2), 54-64, 1998.

[5] DOBRUCKY, B., HAVRILA, R., DUBOVSKY, J.: A Single-Phase Supplied Matrix Converter with Unity Power Factor. PEMC, Prague, 1998.

[6] SeMAil, E., LeVI, E., BOUSCAYROL, A., Kestelyn, X.: Multi-Machine Modeling of Two Connected Series 5-Phase Synchronous Machines: Effect of Harmonics on Control. Proceedings of IEEE European Conference on Power Electronics and Applications, Germany, 10, 2005.

[7] JONES, M., LEVI, E., VUKOSAVIC, S. N.: Independent Control of Two Five-Phase Induction Machines Connected in Parallel to a Single Inverter Supply. Proceedings of IEEE Industrial Electronics Society Annual Meeting (IECON’06), France, 1257-1262, 2006.

[8] FRIVAldSKY, M., DOBRUCKY, B., SCELBA, G., SPANIK, P., DRGONA, P.: Bidirectional Step-Up/Step-Down DC/DC Converter with Magnetically Coupled Coils. Communications - Scientific Letters of the University of Zilina, 15(3), 21-25, 2013. 


\section{kOMNIIKCCle}

[9] NEFT, CH. L., SCHAUDER, C. D.: Theory and Design of a 30-hp Matrix Converter. IEEE Transactions on Industry Applications, 28(3), 546-551, 1992.

[10] SCHAUDER, C. D.: Hidden DC-Link AC/AC Converter Using Bilateral Power Switches. United States Patent 4,642,751.

[11] JUSSILA, M., TUUSA, H.: Comparison of Direct and Indirect Matrix Converters in Induction Motor Drive. Proceedings of IEEE Industrial Electronics.Conference, (IECON'06), France, 1621-1626, 2006.

[12] REZAOUI, M. M., KOUZOU, A., MAHMOUDI, M. O., NEZLI, L.: Comparison Performances between Two Matrix Converters [3x3] and [3x5] Supplying a Multi-Phases Induction Machine. Journal of Electrical Engineering, 16(1), 217-227, 2016.

[13] CHLEBIS, P., SIMONIK, P., KABASTA, M.: The Comparison of Direct and Indirect Matrix Converters. Proceedings of Progress in Electromagnetics Research Symposium (PIERS 2010), USA, 310-313, 2010.

[14] SCHREIER, L., BENDL, J., CHOMAT, M.: Five-Phase Induction Machine Fed from Ten-Pulse Frequency Converter. Proceedings of 18th International Conference on Electrical Drives and Power Electronics (EDPE), Slovakia, 2011, on CD ROM.

[15] ZASKALICKY, P.: Mathematical Model of a Five-Phase Voltage-Source PWM Controlled Inverter. Electrical Engineering Archiv für Elektrotechnik, Springer-Verlag GmbH, Germany, 2017. Published on-line 12-09-2017.

[16] FANG, Y., TAN, G., LIU, H.: Space Vector Modulated Three-Phase to Two-Phase Matrix Converter. Proceedings of International Conference on Electrical Engineering, 2009.

[17] SCHREIER, L., BENDL, J., CHOMAT, M.: Operation of Five-Phase Induction Motor after Loss of One Phase of Feeding Source. Electrical Engineering, 99(1), 9-18, 2017. 